\title{
University cities' evolution in context of human capital accumulation
}

\author{
Olga I. Gevorgyan ${ }^{1 *}$, Nikolay N. Minaev ${ }^{2}$, and Ekaterina A. Zharova ${ }^{1}$ \\ ${ }^{1}$ Tomsk State University, 36 Lenin Ave., Tomsk 634050, Russian Federation \\ ${ }^{2}$ Tomsk State Pedagogical University, Tomsk, ul. Kievskaya 60, Tomsk 634061, Russian Federation
}

\begin{abstract}
In the context of global competition, attracting and retaining talent is the most important common goal of universities and cities. Universities have long played an important role in the competitiveness of cities, regions and the country as a whole, as they contribute to the accumulation of human capital. The interaction of the city and the university can be observed from the time of their formation. In this paper, the authors considered a parallel analysis of the development (evolution) of two different socio-economic systems such as the university and the city from antiquity to the present. Based on this analysis, we can conclude that universities have played a significant role in the development of cities, and cities, in turn, have led to the emergence and development of universities. The role of universities was that they were both centers of education and centers of research. It was within the framework of universities that the results of scientific research appeared, which moved cities up in evolution.
\end{abstract}

Keywords: evolution, university city, human capital, industry 4.0

\section{Introduction}

In modern conditions of increasing global competition, the process of human capital accumulation is a key element in ensuring national security. That is why, most important places of accumulation of human capital become the so-called "university cities", which, in fact, is a two-component form of socio-economic subsystem, where both the city and the located on its territory university are clearly distinguished and the latter has distinctive features of a separate settlement. There is no clear concept of a "university city" in modern scientific literature. Most often, the definition "college town" appears in foreign sources. In the American College Town, the American researcher Blake Gumprecht defined it as "a city in which a college and university, as well as the culture they create, have a dominant influence on the character of society [1]. However, in our opinion, the concept of "university city" / "college town" requires serious scientific study. Therefore, the research of "university cities", their socio-economic essence and nature, should begin with the study of the evolution of cities and universities as separate entities, which are closely intertwined with a variety of

\footnotetext{
*Corresponding author: dobrynina_oly@mail.ru
} 
interactions. The information base of the research is formed on the basis of scientific works of domestic and foreign authors, materials of the periodical press, materials of scientific and practical conferences on the studied problem. This research is based on a dialectical method that determines the study of socio-economic phenomena in their constant development and relationship.

\section{Objects and methods of research}

The authors identify seven very closely related stages of development of cities and universities, which in their turn fit into the paradigm of "industrial revolutions" (Fig.1).

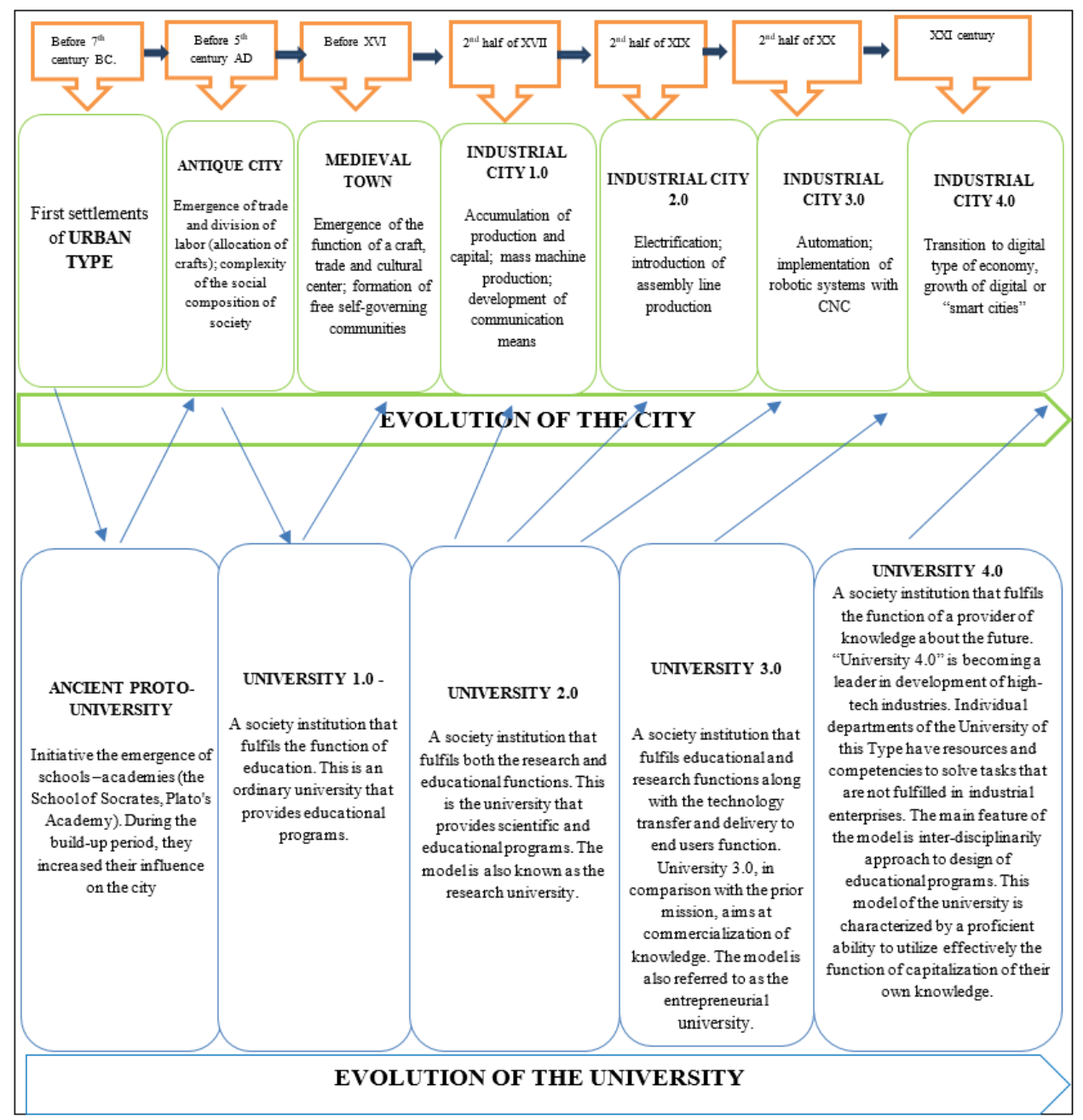

Fig. 1. Evolution of cities and universities.

Having emerged due to the influence of society (development of cities and urban culture, monetary economy, improvement of agricultural production and growth of human welfare), universities in their turn began to change the structure of society that gave birth to them, enriching and complicating it, affecting the development of European science, culture and education in general [2]. Ancient proto-universities served as a powerful tool for development of education. During the period, many important inventions and discoveries 
were applied in construction, navigation and everyday life. They did not have a revolutionary character, but they contributed to gradual development of material and technical thought of the humanity. Main technical achievements of antiquity were focused on war weapons, but many discoveries were also utilized for peaceful purposes, especially agriculture. Ancient science achieved certain results, which later served as a basis for advance of modern science[3].

Universities in medieval Europe emerged in direct connection with the growth of cities, i.e. with urbanization of western European society[4]. They became a fundamentally new phenomenon in European socio-cultural life. They were not associated with ancient higher education institutions. The content and forms of education were developed and improved together with the development of medieval cities, growth of social activity of citizens, their intellectual needs and interests. Development of commodity-money relations in medieval cities created demand for educated people and experimental knowledge [5]. The city needed artisans, doctors, lawyers; the church needed theologians, therefore the "customers" were the city and the church. It is worth noting that at this stage there appeared a link between the university and the city[6].

With the transition to industrial stage of urban development, the state's demand for educated citizens increased dramatically. During the period of industrial society, new higher educational institutions, polytechnic and specialized institutes and academies emerged. Education became comprehensive [7]. Direct relationship with industrial partners became common. Cities were beginning to become completely dependent on universities (and their products - inventions and graduates). At this stage not the city but the state became the "customer".

University 3.0 emerged in the period when industry was reaching its maturity and transformation, which is usually referred to as a "post-industrial transition", was at its start. A superstructure was formed over the industry - companies using factories as material, creating complex patterns of activities that included development of new product samples (industrial laboratories), production chains (factories), product sales and market development (sales and marketing divisions), after-sales service for product users (service divisions) [8]. The state needed to develop economy and create innovations. Scientific development combined education of high-quality specialists and postgraduate students with entrepreneurial function as well as implementation of projects for integration of new technological structures and advanced technologies into economy. At this stage, there appeared a link between the university, the state and production. The "customer" was not only the state, but also the production sector.

Rapid pace of industrial development defines a new model for specialists' training. "Industry 4.0" is associated with a wide-scale introduction of cyber-physical systems into production process and catering for human needs, in areas of everyday life, work and leisure[9]. These increase requirements not only for knowledge, skills and abilities, but also for the level of personal development that determines the quality of human capital. In this regard, the new generation of universities (universities 4.0) should make top priority of their activities the mission to graduate not only professionals possessing high qualifications, but also high moral and ethical attitudes, able to contribute to building a more sustainable society [10]. University 4.0 should be able to determine the trajectory of economic development, which is to entail modernization of business, production and research companies, changes in regional planning and development strategies. Nowadays, many universities are beginning to think of themselves as urban and are turning themselves into platforms for interaction between subjects in planning urban and regional development. By analogy with other countries, both regions and universities themselves have a request for closer cooperation between universities, as well as between universities and other entities. For example, the idea of a united Tomsk university as a consortium of universities with preservation of 
organizational autonomy has been actively discussed recently. Universities are also directly or indirectly involved in solving social problems, such as employment and migration in the region, legal awareness, social stability, etc. There is a change of "customer" which is now represented by different communities (formal and informal), transnational organizations, and individuals.

Based on the given research, a number of patterns of development of universities and their cities were identified, which lead to a new understanding of the origin and evolution of "university cities":

1. Universities (proto-universities) were born in cities that were actively involved in global competition for trade, economic and military dominance (for example, schoolacademies of Ancient Greece and Ancient Rome).

2. Universities provided and initiated gradual transition of cities from one industrial era to another.

3. Until XVII century, universities were deeply dependent on cities they were in and relied on political, financial and economic support of local authorities for their existence.

4. Processes of state centralization (especially in Europe) and loss of the previous level of political and economic independence of individual cities created new opportunities for universities on an international scale - they began to acquire new subjectivity and by the end of XX century became major international research and educational centers with significant financial opportunities.

5. University science and education assisted in formation of an "industrial city" and over time began to determine ways of socio-economic development not only of their cities, but also to influence other cities and countries on a global scale.

6. "Cities-universities" (Oxford, Cambridge, Harvard, etc.) having turned into junctional centers of human capital accumulation became "university cities", i.e. there is a link between cities and universities in terms of managemental and economic functioning [11].

7. The number of "university cities" is rapidly growing with advent of the "digital revolution", and their influence on global processes is becoming crucial.

\section{Results and discussion}

Universities have played a significant role in development of cities, and cities, in their turn, contributed to emergence and development of universities. The role of universities was that they were both centers of education and centers of scientific research. Results of scientific research, which appeared within the framework of universities, moved cities up the evolution ladder. At first universities became a separate socio-economic subsystem that was only slightly dependent on their cities but later they managed to become national strategic centers for accumulation of human capital and began to determine trends of socio-economic development of their cities. Thus, the process of formation and development of a new "dual" socio-economic subsystem - "university city" - is currently underway.

\section{Conclusion}

Currently, relevance of works devoted to the study of the "university city" phenomenon is growing. In this paper, the parallel analysis of formation and development (evolution) of universities and cities has been conducted for the first time. It is obvious that in the future it is necessary to study the essence and nature of the functioning of cities with a pronounced "scientific and educational industry jacket" more deeply to formulate and introduce the concept of "university city" into scientific usage. 


\section{References}

1. B. Gumprecht, The American college town. Geographical Review 93 1, 51-80 (2003)

2. E.B. Kuznetsov, and A. A. Engovatova, «Universities 4.0»: points of growth of the knowledge economy in Russia. Innovations 5211 3-9 (2016)

3. E.N. Kirillova, Medieval city: about new old criteria. Middle ages 783 77-93 (2017)

4. E.V. Neborsky, Reconstructing the model of the University: transition to the format 4.0. Internet journal «World of science» 54 1-10 (2017)

5. V.V. Ryapolov, The emergence of medieval universities: content and forms of education. Business and design review 1915 (2018)

6. N.V. Novikova, and S.S. Chudinova, Definition of the concept «Industrial city» in the socio- historical aspect. Journal of new economy 322 100-104 (2008)

7. O.I. Bogdanovich, et al. The role of universities in economic development. Bulletin of PSU Series: Economics 225 15-22 (2015)

8. V.S. Efimov, and A.V. Lapteva, University 4.0: Philosophical and methodological analysis. University management: practice and analysis 211 16-29 (2017)

9. I.V. Naletova, Humboldt university in the dynamics of university education development. Bulletin of TSU 9 7-12 (2010)

10. L.V. Alekseeva, et al. Three missions of the university: education, science, societ. Moscow MAKS Press 440 (2019)

11. P. Hall, The university and the city. GeoJournal 41 301-309 (1997) 